\title{
Intestinal Helminth Infection among Primary School Children in Ntezi Area of Ebonyi State, Nigeria
}

\author{
Ani, O. C. and Akamnonu, N. J. \\ Department of Applied Biology, Ebonyi State University, Abakaliki, Ebonyi State, Nigeria
}

Corresponding author: Ani, O. C. Department of Applied Biology, Ebonyi State University, Abakaliki, Ebonyi State, Nigeria. .Phone: 08076688913

\begin{abstract}
A survey of intestinal helminth infections among primary school children in Ntezi, Ishielu LGA of Ebonyi state, Nigeria was undertaken using direct smear and egg floatation techniques. A total of three hundred stool samples were collected from pupils of both sexes and examined. Their ages ranged from six to fourteen years old. 81 out of the 300 samples were positive for various intestinal helminths with hookworm accounting for 16.7\%; Ascaris lumbricoides, 8\%; Trichuris trichura,1\%; Strongyloides stercoralis, 0.67\%; and mixed infections of hookworm and Ascaris $0.67 \%$. Age and sex affected the pattern of infections. Pupils aged 6-8 years had the highest prevalence of 40(35.6\%); 9-11 years $32(33.3 \%)$ and $12-14$ years had $9(10 \%)$. Infection was more in females $(33.3 \%)$ than in males (19.6\%). Pupils that defecate in the bush had highest infection of 15\%; pit toilet $6.7 \%$; stream $5 \%$ while those that use water closet had no infection. Assessment on source of water showed that pupils who use stream water had the highest infections of 45 (58\%); well water 23(28.4\%); borehole 11(13.6\%) and rainfall had no infection. Infections were detected in all the schools investigated. The study showed that school pupils carry heavy intestinal parasite burden and the socio-economic status of parents, source of water and methods of fecal wastes disposal all had contributory effects on the prevalence of infections. To reduce the prevalence and effects of helminth infections in the area, school-based de-worming campaign, public health awareness programmes, improved water supply and improved socio-economic status of the populace are recommended.
\end{abstract}

Keywords: Helminths, Ascaris, Trichuris, Strongyloides, Tropics, Infection

Introduction

Helminths are a group of helminth parasites that spend an essential part of their asexual life cycle in the soil (WHO, 1998). Their immature stages (eggs) require a period of development or incubation in the soil before they become infective preparatory to transmission (WHO, 1987). Soil transmitted infections represent a major public health problem in poor and developing countries and have constituted a universal burden which does not only depend on regional ecological condition but also on local standard of social and economic development of the people (Ukpai and Ugwu, 2003). The commonest of such parasites are Strongyloides stercoralis, Trichura trichuris, Ascaris lumbricoides, Toxocara spp, Diphylidium caninum, Necator americanus and Ancylostoma duodenale (Eneanya and Njom, 2003).

It is estimated that almost 2 billion people are infected with one or more of these soil transmitted helminths accounting for up to $40 \%$ of the global morbidity from infectious diseases exclusive of malaria (Uneke et al., 2007). The public health importance of intestinal helminth infections ranked highest in morbidity rate among school age children who often present much heavy worm infections because of their vulnerability to nutritional deficiency (Bethony et al., 2006). According to Ozumba and Ozumba (2002), intestinal helminths play an important role as contributory factors in the etiology of childhood malnutrition because heavy chronic infection with Ascaris lumbricoides and hookworm may aggravate malnutrition especially among already undernourished children from socio- economically disadvantaged communities. The infections have also been shown to impact negatively on the physical fitness and cognitive performance of the pupils (Nokes et al., 1992).

The prevalence of intestinal helminth infections is promoted by several epidemiological factors such as indiscriminate disposal of human and animal faces, poor personal hygiene, inadequate water supply and other socio-cultural practices such as the use of night soil as fertilizer in the farm. These factors are importance in the transmission of helminth parasites from one host to another and from the environment to a host. Infection may be direct or indirect through secondary sources such as food, water, vegetables and fruits (Umeche, 1991; Okoronkwo, 2000; Akande et al., 2002).

Despite many intervention schemes at controlling these infections, many people especially school age children are still heavily infected. This study therefore was undertaken to access the prevalence level of these infections in the area and determined the possible impact on the pupils, the epidemiological factors that led to the susceptibility of the populace and possibly draw the attention of the local government Authority/Local Health Authorities of the area to the need to adopt community based health polices to ameriorate the problem.

\section{Materials and Methods}

Study area: The study was conducted at Ntezi, in Ishielu local government Area of Ebonyi State. The area has a tropical climate with distinct wet and dry 
seasons. The vegetation is described as a derived savanna with scattered trees, shrubs and farmlands. The inhabitants are predominantly farmers, petty traders, artisans with very few civil servants. Social infrastructures are grossly inadequate and sanitation is generally poor. Indiscriminate defecation in the bush is widely practiced. Sources of water include boreholes, wells and streams.

Sample collection: The study population comprised 300 primary school children aged 6-14 years old. Three primary schools were selected for the study and they include; Central Primary School, Ntezi, Community Primary School, Ulepa and Community Primary School Ezekuna Ezza, Ntezi. Approval for the work was obtained from the Chairman and the Secretary of the Local Government Education Authority, Ishielu Local Government Area, Parent Teachers Association (PTA) and the Head teachers of each of the above schools. Informed consent of the participating pupils was also obtained.

The head teachers and teachers of the affected schools educated their pupils on the necessity of the study. Leak - proof containers were shared to the pupils and they were taught how to collect stool samples at home. Questionnaires were also shared to the participating pupils for collection of demographic information such as age, sex, type of toilet, source of water supply and parents' occupation. Their class teachers helped them fill the questionnaires correctly. The stool samples were collected from the pupils the following morning between 7.55 and 8.45am, correctly labeled and taken to the laboratory for analysis.

Laboratory analysis: The samples were macroscopically examined for colour, consistency, presence of mucus or blood and worm segments. Microscopic examination of each sample was done using direct wet mount and floatation techniques (Cheesbrough, 2000; WHO, 2003).

Statistical analysis: Differences in infection were evaluated using chi-square test and statistical significance was achieved if $\mathrm{P}<0.01$ ).

\section{Results}

The study had an overall prevalence of $81(27 \%)$. Among the different schools investigated, Central Primary School, Ntezi had the highest prevalence of $39(39 \%)$ followed by Community Primary School Ezekuna Ezza, Ntezi 37(37\%) while Community Primary School, Ukpa had the least 5 (5\%) (Table $1)$. The difference in infections between the schools is significant $(P<0.01)$. Out of 138 males examined, $27(19.6 \%)$ were infected and of 162 females examined, 54 (33.3\%) were also infected (Table 2). The difference was also statistically significance $(P<0.01)$. Pupils aged 6-8years had the highest prevalence of intestinal helminth infection 40 (35.6\%); followed by those in 9-11 years 32 (33.3\%) while the lowest prevalence was recorded among those aged $12-14$ years $9(10 \%)($ Table 3$)$. There was significant difference in the trend of infection $(P<0.01)$.

Four species of intestinal helminth parasites were identified in the study, namely: hookworm, 50 (16.7\%), Ascaris lumbricoides 24 (8\%), Trichuris trichura $3(1 \%)$ and Strongyloides stercoralis 2 pupils $(0.67 \%)$ (Table 4$)$. The prevalence of infection was highest among pupils that defecate in bush $46(15 \%)$ followed by those that use pit toilet $20(6.7 \%)$. Those that defecate into streams had $15(5 \%)$ infection while the pupils that use water closet had no infection (Table 5). Statistical analysis showed a significant difference $(P<0.01)$. Distribution of infection in relation to parents' occupation showed that pupils whose parents were farmers had the highest prevalence of 40 (49.4\%) followed by traders 26 (32.1\%), workmen $12(14.8 \%)$ while the least prevalence 3 $(3.7 \%)$ was observed in pupils whose parents were civil servants. On the assessment of infection due to water sources, those who use stream for drinking water recorded the highest prevalence of 47 (58\%), followed by those that use well water 23 (28.4\%) while those that use borehole had the least 11 (13.6\%) (Table 6). The difference in infection trend was statistically significant $(P<0.01)$.

Table 1: Prevalence of intestinal helminth infections in relation to schools in Ntezi Ebonyi State

\begin{tabular}{|c|c|c|c|}
\hline School & $\begin{array}{c}\text { No. } \\
\text { Examined }\end{array}$ & $\begin{array}{c}\text { No } \\
\text { infected }\end{array}$ & $\%$ \\
\hline $\begin{array}{l}\text { Central Primary } \\
\text { School, Ntezi } \\
\text { Community Primary }\end{array}$ & 100 & 39 & 39 \\
\hline $\begin{array}{l}\text { School, Ezekuna Ezza- } \\
\text { Ntezi } \\
\text { Community Primary }\end{array}$ & 100 & 37 & 37 \\
\hline $\begin{array}{l}\text { School, Ulepa } \\
\text { Total }\end{array}$ & $\begin{array}{l}100 \\
300\end{array}$ & $\begin{array}{c}5 \\
81\end{array}$ & $\begin{array}{c}5 \\
27\end{array}$ \\
\hline
\end{tabular}

Table 2: Prevalence of intestinal helminth infection by sex in Ntezi, Ebonyi State

\begin{tabular}{lccc}
\hline Gender & No examined & No infected & $\%$ \\
\hline Males & 138 & 27 & 19.6 \\
Females & 162 & 54 & 33.3 \\
Total & 300 & 81 & 27 \\
\hline
\end{tabular}

Table 3: Distribution of intestinal helminth infection in relation to age of primary school children in Ntezi, Ebonyi State

\begin{tabular}{lccc}
\hline Age group & No Examined & No. infected & $\%$ \\
\hline $\mathbf{6}-\mathbf{8}$ & 120 & 40 & 33.3 \\
$\mathbf{9}-\mathbf{1 1}$ & 90 & 32 & 35.6 \\
$\mathbf{1 2}-\mathbf{1 4}$ & 90 & 9 & 10 \\
Total & 300 & 81 & 27 \\
\hline
\end{tabular}

.Table 4: Prevalence of different intestinal helminths in Primary school Pupils in Ntezi, Ebonyi State

\begin{tabular}{lccc}
\hline Helminth & $\begin{array}{c}\text { No of } \\
\text { Sample }\end{array}$ & $\begin{array}{c}\text { No } \\
\text { infected }\end{array}$ & $\%$ \\
\hline Hookworm & 300 & 50 & 16.7 \\
A. Iumbricoides & 300 & 24 & 8 \\
S, stercoralis & 300 & 2 & .06 \\
Trichuris Trichura & 300 & 3 & 1 \\
Mixed infection & 300 & 2 & .06 \\
Total & 300 & 81 & 27 \\
\hline
\end{tabular}


Table 5: Distribution of intestinal helminth infection in relation to toilet types In primary school pupils in Ntezi, Ebonyi State

\begin{tabular}{lccc}
\hline Toilet Type & No. Examined & No. infected & $\%$ \\
\hline Bush & 300 & 46 & 15.3 \\
Pit & 300 & 20 & 6.7 \\
Stream & 300 & 15 & 5 \\
Water closet & 300 & 0 & 0 \\
\hline
\end{tabular}

Table 6: Prevalence of intestinal helminth infection in relation to water in Primary school children in Ntezi, Ebonyi State

\begin{tabular}{lccc}
\hline Water Source & No of sample & No. infected & $\%$ \\
\hline Borehole & 81 & 11 & 13.6 \\
Well & 81 & 23 & 28.4 \\
Stream & 81 & 47 & 58 \\
Rainfall & 57 & 0 & 0 \\
Total & 300 & 81 & 27 \\
\hline
\end{tabular}

\section{Discussion}

This study recorded prevalence of 81 (27\%) intestinal helminth infections among primary school pupils agreed with the reports of WHO (2000); Murray et al.,(2003); Anantaphruti et al.,( 2004); Dakul et al,(2004) and Uneke et al.,( 2007). However, it was considerably lower than those of Odikamnoro and Ikeh (2004); Nock et al, (2003); ljagbone and Olagunju (2006); Adeyeba and Akinlabi (2002) who reported $76.1 \%, 52 \%, 72 \%$ and $64 \%$ respectively in their studies in different parts of Nigeria.

Variations in prevalent rates in these studies were reflection of the local endemicity, poor sanitary standard and personal hygiene, high level of poverty and illiteracy prevalent in the various study areas. Several reports showed that prevalence of intestinal helminthes was higher during rainy than dry seasons because wet or damp soil favours the development of helminth eggs( Nock et al.,2003; Vander-Hook et al.,(2003);Dakul et al.,(2004). Similarly, areas with improved environmental sanitation and personal hygiene, low poverty and high literacy levels showed low prevalence of helminth infection (ljagbone and Olagunju, 2006).

Four species of helminth parasites were identified namely; Hookworm 16.7\%, Ascaris lumbricoides $8 \%$, Trichuris trichura $1 \%$ and Strongyloides sterocoralis $0.67 \%$. This was consistent with earlier reports of Adeboye (1999), Phiri, et al., (2000), Dakul et al., (2004), ljagbone and Olgunji (2006) and Odikamnoro and Ikeh (2004) and Uneke et al., (2005). This indicated that infections caused by these groups of parasites were common among rural and urban populations in Nigeria. More females were infected (33.3\%) than males $(19.6 \%)$ which was consistent with Alakija (1986) and Odikamnoro and Ikeh (2004) but contrasted with the reports of Dakul et al, (2004); Nock et al., (2003) and Uneke et al., (2005) where infections were higher in males than females.

Children in the age range of 6-8 years had the highest prevalence of $40(35.6 \%)$ while those in the age range of $12-14$ years had the least $9(10 \%)$. This agreed with the earlier reports of Okpala (1956); Luka et al, (2000) and Naish et $\mathrm{al},(2004)$. The results indicated that children in lower age groups probably spend more time out doors either playing or washing ,thus are more often in contact with the soil; and may usually eat with unwashed hands. Increased level of awareness and personal hygiene may result in reduction of infection among pupils in higher age groups. There was also high prevalence of infection among children that defecate in the bush $15 \%$, followed by those that use pit toilets $6.7 \%$. Source of water supply was also a predisposing factor. Pupils who use stream and well water had high prevalent rates of $58 \%$ and $28.4 \%$ respectively and this agreed with reports of Ozumba and Ozumba (2002) at the University Teaching Hospital Enugu and that of Phiri et al, (2000) at the Department of Community Health College Medicine, Malawi.

The debilitating effects of intestinal helminth infections on school children include; school absenteeism, malnutrition, mental backwardness, emaciation and retarded growth. Therefore both State and Local Health Authorities as well as non-governmental organizations should adopt health polices that will lead to control and management of these infections. This could come inform of routine deworming of school children, improvement on the environmental disposal of both human and other domestic wastes, provision of portable water in the affected areas and health education on the dangers of infections, mode of transmission and prevention of these parasites.

\section{References}

Adeboye, A.A (1999). Intestinal helminths infection in rural school children in Oshogbo, Osun State. West African Medical Journal, 71:792-796.

Adeyeba, O.A and Akinlabi, A.M.J (2002). Intestinal parasitic Infections among school children in a rural community, Southwest Nigeria. Nigeria Journal of Parasitology, 23:11-18.

Akande, D.O.; Adeleke, E.O. and Akinwale, O. (2002). The prevalence of intestinal contaminants of fruits sold in some markets in Lagos, Nigeria. Journal of Tropical Bioscience, 2:33-35.

Alakija, W. (1986). Prevalence of intestinal parasitic diseases in rural area of Nigeria. Annal of Tropical Medicine and Parasitology. 80:545-549.

Anantaphruti, M.T.; Waikagul, J.; Maipanich, W.; Nuamtanong, S. and Pubampen, S. (2004). Soil-transmitted helminthiasis and health behaviours among school children and community members in a West Central Border area of Thailand, Southeast Asia. Tropical Medicine and Internantional Health, 9 :1012-1015.

Bethony, J.; Brooker, S.; Albonica, M.; Geiger, S.M.; Loukas, A.; Diemert, D. and Hotez, P.J. (2006). Soil-transmitted helminth Infections: ascariasis, trichuriasis, and hookworm. Lancet, 367: (9521):15211532.

Cheesbrough, M.F. (2000). Medical Laboratory Manual in Tropical Countries. Part 2-Low 
Price Edition Butterworth Company New York.

Dakul, D.A.; Onwulili, C.O.E.; Uneke, C.J. and Nwabigwe, E.U. (2004). Assessment of intestinal helminth infections in Utan, Plateau state. Journal of Health and Visual Sciences 6(2):70-74.

Eneanya, C.I. and Njom, V.S. (2003). Geohelminth contamination of some common fruits and vegetables in Enugu, Southeast, Nigeria. Nigerian Journal of Parasitology, 24:123128.

ljagbone, I.F. and Olagunju, T.F. (2006). Intestinal Helminth parasites in school children in Iragbiji, Boripe Local Government, Osun State, Nigeria. African Journal of Biomedical Research, 9: 63-66.

Luka, S.A.; Ajagi, I. and Umoh, J.U. (2000). Helminthiasis among primary school children in Lere Local Government Area, Kaduna State, Nigeria. Nigerian Journal of Parasitology, 21:109-116.

Murray, M.K.; Bradley, K.C. and Palmer, D.R. (2003). g64 responses to antigens of children intestinal helminths: Potential for use in large-scale epidemiological studies. Bulletin of World Health Organization, 74:381-386.

Naish, S.; McCarthy, J. and Williams, G.M. (2004). Prevalence, intensity and risk factors for soil-transmitted helminth infection in a South Indian fishing village. Acta Tropica. 91:177-87.

Nock, I.H.; Duniya, D. and Galadima, M. (2003). Geohelminth eggs in the soil and stool of pupils of some primary schools in Samaru, Zaria, Nigeria. Nigerian Journal of Parasitology, 24:115-122.

Nokes, C., Grantham-McGregor, S.M., Sawyer, A.C., Cooper, E.S. and Bundy, D.A.P. (1992). Parasitic helminth infection and cognitive function in school children. Proceedings of Royal. Society of London, 247:77-81.

Odikamnoro, O.O. and Ikeh, I.M. (2004). Prevalence of intestinal helminthic infections among primary school pupils in kpiri-kpiri sub-urban Area of Abakaliki, Ebonyi State. Nigerian Journal of Parasitology, 24:71-79.

Okoronkwo, O.M. (2000). Detection and enumeration of parasitic eggs in irrigated vegetables and salad crops in plateau state, Nigeria. Journal of Medical Laboratory Science, 9:30-36.

Okpala, I. (1956). The incidence of intestinal parasites among school children in Lagos, Nigeria. West African Medical Journal, 12:148-157.

Ozumba, U.C. and Ozumba, N.O. (2002). Patterns of helminth infections in the human gut at the University of Nigeria Teaching Hospital, Enugu, Nigeria. Journal of Health Science, 48(3):263-268.

Phiri, K.C.; Whitty, J.M.; Graham, S.M. and Sembatya, G. (2000). Urban/rural difference in prevalence and risk factors for intestinal helminths infection in southern Malawi. Annal of Tropical Medicine and Parasitology, 94:383-387.

Ukpai O.M. and Ugwu, C.D. (2003). Prevalence of Gastro-intestinal tract parasities in primary school children in Ikwuano Local Government Area of Abia State, Nigeria. Nigerian Journal of Parasitology, 24:129130.

Umeche, N. (1991). Parasite ova and cysts on fruits sold in Calabar. Nigerian Journal of Parasitology, 12:85-87.

Uneke, C.J., Eze, K.O., Oyibo, P.G., Azu, N.C. and Ali, E. (2007). Soil-transmitted helminth infection in school children in Southeast Nigeria: the public health implication. The Internet Journal of Third World Medicine, 4(1): 1-2.

Vander - Hook, W.; De, N.V.; Konradsen, F.; Cam, P.D.; Hoa, N.T.; Toan, N.O. and Congle, D.(2003). Current status of soil transmitted helminths in vietnam. American Journal of Tropical Medicine and Hygiene, 70 (2); 334-336

WHO (1987). Prevention and control of intestinal parasitic infections. WHO Tech. Report Series, N 749.

WHO (1998). Intestinal parasite control, burden and trends. Document No. WHO/CTD/HTM 98:24.

WHO, (2000). Gender differences in growth of school aged children with schistosomiasis and geohelminth infections. Journal of Tropical Medicine, 55(2): 150-156.

WHO, (2003). Manual of Basic Techniques for a Health Laboratory. 2nd edition, Geneva. 152pp 